\title{
Ergatividade cindida, papel temático e causativização na língua Ka'apor ${ }^{1}$
}

Split ergativity, theta role and causative verbs in the Ka'apor language

\author{
Fábio Bonfim Duarte \\ Universidade Federal de Minas Gerais \\ Mário Alexandre Garcia \\ Universidade Federal de Minas Gerais
}

\begin{abstract}
This paper examines the Case and theta role assignment to DPs in the Ka'apor language. Our hypothesis is that Ka' apor manifests a split Case system, which may be triggered either by the semantic nature of stative predicates or by the DPs that receive the theta role "paciente/theme". In addition to this, we propose that the enclitic particle [.ke] may be described as the (absolutive) Case and thematic role assignment to object and to subject of unaccusative verbs. We also postulate that the causative prefix $\{\mathrm{mu}-\sim \mathrm{m}-\}$, which occurs in ergative predicates, is the morphological manifestation of the light verb. Finally, we propose to extend the obligatory Case parameter in order to explain the split Case system of the Ka' apor. Thus, we suggest that Spec-TP is activated for assigning the (nominative-absolutive) structural Case to the subjects of active transitive, unergative and unaccusative verbs and Spec-vP is activated for assigning the absolutive Case to the object and to the subject of stative verbs.
\end{abstract}

Keywords

Split Case, theta role, causative verb and Obligatory Case Parameter (OCP). 


\section{Resumo}

Este artigo trata da atribuição de Caso, papel temático e da realização do verbo causativo na língua Ka' apor. Procuramos demonstrar que a língua Ka'apor manifesta uma cisão no sistema de Caso, a saber: nominativo-absolutivo. Esta cisão é consequiência da natureza semântica dos DPs e dos verbos estativos. Com relação aos verbos estativos, o caso absolutivo é marcado por meio dos prefixos absolutivos. Já os DPs sujeito de verbos inacusativos e estativos, e objeto de verbos transitivos recebem caso absolutivo por meio da partícula [.ke], que codifica, além do Caso, o papel temático [+paciente/tema]. Sobre o verbo causativo, propomos que o prefixo $\{\mathrm{mu} \sim \mathrm{m}\}$, que ocorre em predicados ergativos, é a manifestação morfológica do verbo causativo leve. E, por fim, buscamos explicar a cisão no sistema de Caso do Ka'apor, utilizando o Parâmetro de Caso Obrigatório (OCP). Sugerimos que Spec-TP é ativado para atribuir caso estrutural (nominativoabsolutivo) aos sujeitos de verbos transitivos, inergativos e inacusativos e Spec-vPé ativado para atribuir o Caso absolutivo ao objeto e ao sujeito de verbos estativos.

\section{Palavras-chave}

cisão no sistema de Caso, papel temático, verbo causativo e Parâmetro Obrigatório de Caso (OCP) 


\section{INTRODUÇÃO}

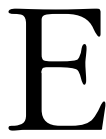

ste artigo tem por objetivo mostrar que, na língua Ka' apor ${ }^{2}$, diferentemente de outras línguas Tupi-Guarani, é possível estabelecer uma nítida distinção sintática entre predicados inergativos e inacusativos, se tomarmos por base o papel temático e o Caso (estrutural) que é atribuído ao DP sujeito desses verbos. Buscamos ainda motivar que o prefixo causativo $\{\mathrm{mu}-\sim \mathrm{m}-\}$, que pode ser acrescentado a verbos descritivos/estativos, inacusativos, inergativos e até a verbos transitivos, pode ser visto como sendo o reflexo, na morfologia, do verbo leve (light verb) que encabeça o núcleo da estrutura v-VP. Conforme análise que desenvolveremos na seção 3, este prefixo pode c-selecionar VPs monádicos e diádicos, produzindo verbos ergativos de dois lugares.

Os dados colhidos até o momento mostram que o DP sujeito dos verbos intransitivos descritivos/estativos e inacusativos, ao contrário do DP sujeito dos verbos inergativos e transitivos de ação, pode vir marcado por meio da partícula [.ke], que geralmente vem enclítica ao DP sobre o qual estabelece escopo sintático-semântico, conforme se vê pelos dados seguintes:

\section{INACUSATIVOS}
(1) ihe ke
$a$-'ar
eu ABS
eu-cair
"Eu caio"

(Silva, 2001, p. 47)
(2) ihẽ ø-jiwa ke meu POSs-braço ABS
"Meu braço quebrou"
$\begin{array}{ll}\text { u-pen } & t \tilde{\imath} \\ \text { 3-quebrar } & \text { REP }\end{array}$

(Silva, 2001, p. 19) 


\section{DESCRITIVOS}

(3) a'e ta ke i-akang ke i-juhar fï (Silva, 2001, p. 9) ela PL ABS POSS-cabeça ABS ABS-ter coceira REP

"Elas, as cabeças deles estão coçando [lit: têm coceiras]."

Conforme veremos na seção 2, uma das principais funções da partícula [.ke] é tornar visível o papel temático [+AFETADO/+PACIENTE] dos DPs com os quais coocorre. Por sua vez, DPs sujeitos agentivos de verbos inergativos não recebem essa partícula. É interessante observar que essa restrição sintática sinaliza uma importante diferença na marcação dos sujeitos dos verbos monoargumentais na língua Ka'apor. Comparem os dados em (1) a (3) de predicados inacusativos e descritivos com os exemplos em (4) e (5), de predicados inergativos:

\section{INERGATIVOS}
(4) jane ja-jengar ja-in (Silva, 2001, p. 20) nós nós-cantar nós-estar
"Nós estamos cantando"

(5)

$\begin{array}{llll}\begin{array}{l}\text { arauxu } \\ \text { Araújo } \\ \text { "Araújo gritou muito" }\end{array} & \text { 3-gritar } & \text { mu } & \text { (Kakumasu, J. 1986, p. 331) }\end{array}$

Todavia, além do DP sujeito dos verbos descritivos e inacusativos, em (1) a (3), também DPs na função sintática de objeto podem vir marcados por meio da partícula [.ke], conforme se vê pela presença dessa partícula junto aos DPs objetos dos predicados transitivos em (6) a (11). Notem ainda que os DPs sujeitos dos verbos transitivos não vêm marcados com a partícula [.ke]:

\section{TRANSITIVOS}
(6) ihe ta'yn ke a-mu-'e
eu criança ABS eu-CAUS-aprender
"Eu ensino a criança" [lit: faço-a aprender]


(7)

$\begin{array}{llll}\text { ihe } & \text { narãj } & \boldsymbol{k} \boldsymbol{e} & \text { a-pirok } \\ \text { eu } & \text { laranja } & \text { ABS } & \text { eu-descascar }\end{array}$

"Eu descasco a laranja"

(8)

$\begin{array}{lllll}\text { ta'yn }_{i} & h_{j} \text {-okwen } & \text { ke } & \varnothing_{i} \text {-kina } & \text { (Caldas, 2001, p. 22) } \\ \text { criança } & \text { POSS-porta } & \text { ABS } & \text { 3-fechar } & \\ \text { "A criança } a_{i} \text { fecha a porta }\left(\text { dela }_{j}\right) \text { " } & \end{array}$

(9) ihẽ a'e ke a-mи-e'o

eu ele ABS eu-CAUS-ter cansaço

(Silva, 2001, p. 22)

"Eu o cansei"

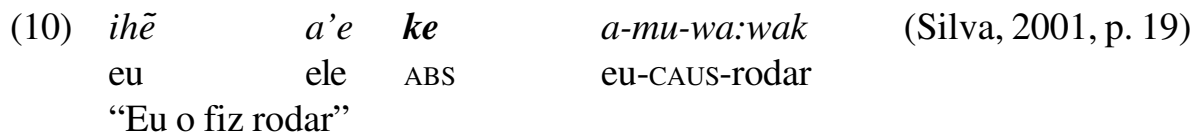
(11) Cristina ihẽ Ø-jiwa ke Ø-pyhyk (Caldas, 2001, p. 22)
Cristina minha poss-braço ABS 3-segurar
"Cristina segura meu braço"

Tomando por base o que o conjunto de dados apresentados indica, a hipótese que exploraremos neste trabalho é de que a ocorrência da partícula [.ke] junto a DPs não é aleatória, mas, ao contrário, tem a função gramatical de assinalar a natureza semântica [+AFETADO/+PACIENTE] do sujeito de verbos inacusativos e do objeto de verbos transitivos de ação, fato que sugere um interessante alinhamento sintático-semântico entre o DP sujeito de verbos intransitivos (descritivos e inacusativos) com o DP objeto. Esse tipo de alinhamento lembra muito o sistema que Dixon $(1979,1994)$ denomina ergatividade cindida (split ergativity). Nessa linha de investigação, outro propósito deste artigo é encontrar uma resposta para a questão formulada em (12):

(12) Será a partícula [.ke] reflexo da atribuição do papel theta [+AFTEADO/ +PACIENTE] e do Caso estrutural aos DPs na função sintática de sujeito (S) de verbos descritivos/estativos, inacusativos e de objeto $(\mathrm{O})$ de verbos transitivos de ação? 
Para responder a essa e a outras questões relativas à predicação verbal na língua Ka'apor, dividimos este texto em quatro seções. Na seção (1), fornecemos uma breve descrição do sistema de concordância que se dá entre o sujeito e o verbo em predicados monoargumentais e transitivos; na seção 2, tomando por base as propriedades sintático-semânticas da partícula [.ke], propomos subdividir os verbos intransitivos da língua Ka'apor em, pelo menos, duas subclasses: os descritivos/estativos e inacusativos, por um lado, e os inergativos, por outro; na seção 3, averiguamos os tipos de alternância causativa que aumentam a valência de predicados descritivos, inacusativos, inergativos e transitivos e propomos que o prefixo $\{\mathrm{mu}-\sim \mathrm{m}-\}$ seja interpretado como realização do verbo leve causativo, o qual equivale aos verbos FAZER/ CAUSAR/PROVOCAR; e, por fim, na seção 4, estando ciente da cisão na marcação de Caso dos argumentos (S) dos predicados monoargumentais, utilizamos o mecanismo de atribuição de Caso (estrutural), acompanhando o Parâmetro Obligatório de Caso (OCP), conforme proposto por Laka (1993) e Bobaljik (1993).

\section{SISTEMA DE CONCORDÂNCIA VERBAL NA LÍNGUA KA'APOR}

Na língua Ka'apor, assim como em outras línguas da família lingüística Tupi-Guaraní, usa-se indistintamente a série de prefixos pessoais nominativos para codificar tanto o sujeito de verbos transitivos como o sujeito de verbos intransitivos (=inacusativos e inergativos). Para facilitar a compreensão dos dados da análise, arrolamos o inventário completo dos pronomes pessoais e dos prefixos pessoais nominativos na tabela 1:

TABELA 1

Marcadores pessoais

\begin{tabular}{l|ll}
\hline Pronomes pessoais & \multicolumn{2}{|l}{ Prefixos pessoais nominativos } \\
\hline ihẽ "eu" & a- & "eu" \\
ne "tu" & ere- "tu" \\
jane "nós" & ja- "nós" \\
pehe "vós" & pe- "vós" \\
a’e "ele(s)/ela(s) & o-/u- "ele(s)/ela(s)-raízes monossilábicas \\
& $\varnothing-$ & "ele(s)/ela(s) - raízes com mais de uma \\
& & sílaba. \\
\hline
\end{tabular}


A ocorrência dos prefixos pessoais nominativos em verbos transitivos, inacusativos e inergativos pode ser visualizada por meio dos paradigmas de conjugação verbal arrolados a seguir. Notem que o prefixo pessoal de terceira pessoa assumirá a forma $\{\mathrm{O}-\}$ quando a raiz verbal contiver mais de uma sílaba, como no paradigma em (15):

\section{INERGATIVO}

$\begin{array}{lll}\text { ihẽ } & \text { a-por } & \text { "eu pulo" } \\ \text { ne } & \text { ere-por } & \text { "tu pulas" } \\ \text { jane } & \text { ja-por } & \text { "nós pulamos" } \\ \text { pehè } & \text { pe-por } & \text { "vós pulais" } \\ \text { a'e } & \text { u-por } & \text { "ele pula" }\end{array}$

\section{$\underline{\text { INACUSATIVO }}$}

$\begin{array}{llll}\text { ihẽ } & \text { ke } & \text { a-'ar } & \text { "eu caio" } \\ \text { ne } & \text { ke } & \text { ere-'ar } & \text { "tu cais" } \\ \text { jane } & \text { ke } & \text { ja-'ar } & \text { "nós caímos" } \\ \text { pehẽ } & \text { ke } & \text { pe-'ar } & \text { "vós caieis" } \\ \text { a'e } & \text { ke } & \text { u-'ar } & \text { "ele cai" }\end{array}$

\section{TRANSITIVO}

$\begin{array}{lll}\text { ihẽ } & \text { a-mu'e } & \text { "eu ensino (alguém)" } \\ \text { ne } & \text { ere-mu'e } & \text { "tu ensinas (alguém)" } \\ \text { jane } & \text { ja-mu'e } & \text { "nós ensinamos (alguém)" } \\ \text { pehẽ pe-mu'e } & \text { "vós ensinais (alguém)" } \\ \text { a'e } & \text { ø-mu'e } & \text { "ele ensina (alguém)" }\end{array}$

Os dados apresentados mostram que o sistema de concordância por meio dos prefixos pessoais nominativos não nos permite estabelecer uma distinção morfossintática clara entre as duas classes de verbos monoargumentais ${ }^{3}$, uma vez que a mesma série de prefixos pode figurar na raiz de verbos inacusativos e de verbos inergativos, independentemente do fato de os inacusativos cselecionarem um DP com o papel theta [+AFETADO] e os inergativos, um DP com o papel theta [+AGENTE]. Todavia, o padrão flexional dos verbos monoargumenatais estativos difere do padrão flexional dos verbos monoargumenatais em (13) e (14) por utilizarem a série de prefixos absolutivos para codificar o DP na função sintática de sujeito. A tabela 2, a seguir, mostra o inventário desses prefixos: 
TABELA 2

Prefixos absolutivos

\begin{tabular}{l|c|c}
\hline & Tema em consoante $^{4}$ & Tema em vogal \\
\hline Adjacência do complemento & $\varnothing$ & $\mathrm{r}-$ \\
Não-adjacência do complemento & i- & h- \\
\hline
\end{tabular}

Os alomorfes $\{\varnothing-\sim \mathrm{r}-\}$ aparecem nos contextos em que o DP vem adjacente ao verbo na estrutura, e os alomorfes $\{i-\sim h-\}$, por sua vez, denotam o fato de o DP não vir imediatamente adjacente ao verbo, seja porque foi deslocado para uma posição mais alta na estrutura, seja porque foi simplesmente omitido. Os exemplos seguintes mostram os contextos de ocorrência desses prefixos:
(16) ihe
r-ury
'ym
(Silva, 2001, p. 5)
eu
ABS-ter alegria
NEG

"Eu não tenho alegria"
(17) ihẽ ø-jeje 'ym ko a-xo (Silva, 2001, p. 5)
eu ABS-estar sozinha NEG aqui eu-estar em movimento
"Aqui, eu não estou sozinha"

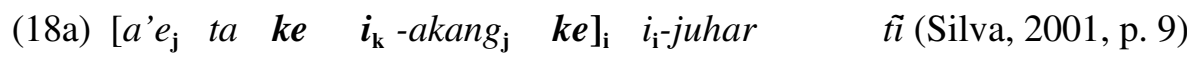
ela PL ABS POSS-cabeça ABS ABS-ter coceira REP

"Elas, as cabeças deles estão coçando"

(18b) $\operatorname{pro}_{\mathbf{i}}$

$i_{\mathrm{i}}$-juhar

$\pi \tilde{\imath}$

ABS-ter coceira REP

"(Elas= as cabeças $)$ estão coçando"
(19a)
$y w y]_{\mathrm{i}}$
$\boldsymbol{h}_{\mathrm{i}}-a k u$
esta PART
terra
ABS-estar quente
"Esta terra está muito quente"
(19b)
$\boldsymbol{h}_{\mathbf{i}}-a k u$
ABS-estar quente
"(Ela = a terra $)$ está muito quente"

(Silva, 2001, p. 8) 
Observem que, em (18a) e (19a), o DP sujeito e o verbo estão situados em posições distintas na estrutura, visto que as propriedades denotacionais dos prefixos $\{\mathrm{i}-\}$ e $\{\mathrm{h}-\}^{5}$ apontam para a não-adjacência do sujeito em relação ao verbo. Esse fato pode ser captado se propomos que o DP sujeito se move para a posição de SPEC de uma projeção funcional acima da posição sintática em que situa o verbo, conforme se vê pela configuração proposta em (18c) e (19c):

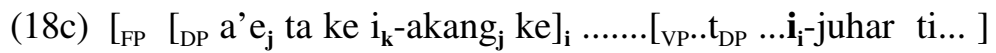

(19c) $\left[_{\mathrm{FP}}\left[{ }_{\mathrm{DP}} \text { ko me'ẽ ywy }\right]_{\mathrm{i}} \quad \ldots \ldots .\left[_{\mathrm{VP}} . . \mathrm{t}_{\mathrm{DP}} \ldots \mathbf{h}_{\mathrm{i}}\right.\right.$-aku $\left.\quad \ldots\right]$

Tomando por base o padrão de concordância sujeito-verbo exposto nos dados (13) a (19), notamos haver uma cisão parcial no sistema de concordância condicionada pela natureza semântica dos predicados estativos/descritivos. Para explicar essa cisão, utilizaremos a terminologia introduzida por Dixon a partir de 1979, de maneira que faremos referência ao argumento agente de um verbo transitivo de ação por meio da sigla (A) e abreviaremos o argumento tema/paciente por meio de $(\mathrm{P})$. Por sua vez, o único argumento dos verbos intransitivos será referido por (S). O sistema nominativo e o sistema ergativo, propostos por Dixon (ibid.), podem ser observados em (20):

(20)

\begin{tabular}{lll}
$\begin{array}{l}\text { Sistema } \\
\text { Nominativo }\end{array}$ & arg. & $\begin{array}{l}\text { Sistema } \\
\text { Ergativo }\end{array}$ \\
\hline Nominativo & $\left\{\begin{array}{l}\text { A } \\
\text { Ergativo }\end{array}\right.$ \\
& \{\} & \\
Acusativo & $\mathrm{O}$ & Absolutivo
\end{tabular}

Concluímos que, nos dados em (13) a (19), o sujeito (S) de verbos estativos é codificado pelos prefixos absolutivos e o sujeito (S) dos verbos inacusativos e inergativos é codificado por meio dos prefixos nominativos. Esse fato nos permite, então, propor a seguinte cisão na codificação do argumento $(\mathrm{S})$ dos predicados monoargumentais ${ }^{6}$ na língua $\mathrm{Ka}$ 'apor: 
(21)

\begin{tabular}{lll} 
Sistema & Sistema \\
Nominativo & arg. & Ergativo \\
\hline
\end{tabular}

Nominativo

$\mathrm{Sa}$<smiles>[Li][12CH2]</smiles>

So

Absolutivo

Vejam que, em (21), (Sa) faz referência ao sujeito de verbos inergativos e inacusativos, por um lado, e (So), ao sujeito dos verbos estativos/descritivos, por outro. Na próxima seção, mostraremos que, embora o sistema de concordância sujeito-verbo marque indistintamente o sujeito [+PACIENTE/ +AFETADO] do verbo inacusativo e o sujeito [+AGENTE] do verbo inergativo por meio dos prefixos pessoais nominativos, a distinção semântica entre os dois argumentos pode ser codificada pela possibilidade de ocorrência da partícula enclítica [.ke] junto ao DP sujeito de verbos inacusativos e descritivos/ estativos. O comportamento dessa partícula nos servirá como um interessante diagnóstico sintático-semântico para distinguirmos os verbos inacusativos (e também os descritivos/estativos) dos verbos inergativos.

\section{PROPRIEDADES SINTÁTICAS E SEMÂNTICAS DA PARTíCULA "KE"}

Dados retirados dos trabalhos elaborados por Kakumasu, J. (1986); Kakumasu, J. \& Kakumasu, K. (1990), Silva (2001) e Caldas (2001) nos revelam que a partícula [.ke], em geral, denota que o argumento envolvido no evento recebe a interpretação de [+AFETADO/+PACIENTE]. Tal intuição é, particularmente, confirmada quando comparamos a ocorrência dessa partícula no objeto de verbos transitivos com a sua ocorrência no sujeito de predicados descritivos/estativos e inacusativos, conforme se vê em (22) a (29):

\section{ORDEM [SOV]EM TRANSITIVOS DE AÇÃO}
(22) a'erehe
taru Nexi $\boldsymbol{k}$
ø-jo'ok
(Kakumasu, J., 1986, p. 327)
por esta razão Taru Nexi ABS 3-pegar
"Por essa razão, Taru pegou Nexi”. 


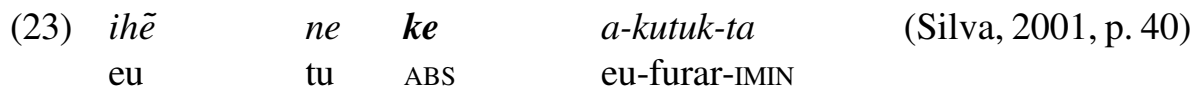

"Eu vou te furar"

(24) a'e 'ok ke ø-mujã

(Silva, 2001, p. 39)

ele casa ABS 3-fazer

"Ele faz casa".

\section{ORDEM [SV] EM DESCRITIVOS/ESTATIVOS}

\begin{tabular}{|c|c|c|c|}
\hline Ana & ke & $h-e^{\prime} \tilde{o}$ & 'y (Caldas, 2001, p. 26) \\
\hline Ana & $\mathrm{ABS}$ & ABS-ter cansaço & PERF.1 \\
\hline
\end{tabular}

\section{$\underline{\text { ORDEM [SV]EM INACUSATIVO }}$}

(26) ihe ke a-'ar

(Silva, 2001, p. 47)

eu ABS eu-cair

"Eu caio"

(27) arapari ke u-'e ta ki (Caldas, 2001, p. 62) lamparina ABS 3-apagar IMIN INT "A lamparina vai apagar".

(28) ta'yn ta ke ø-jixi'u ja-jur rahã criança PL ABS 3-chorar nós-vir quando "As crianças choravam, quando nós viemos." (Silva, 2001, p. 46)

\section{ORDEM [VS]EM INACUSATIVO}

(29) a-pyhyj ta ihe ke

1-cochilar IMIN eu ABS

"Eu (tenho necessidade de) cochilar".

(Silva, 2001, p. 46)

Tomando por base os dados mostrados, defenderemos doravante a hipótese de que a função da partícula [.ke] na língua Ka'apor é tornar visível, ao nível do componente sintático-semântico, o papel temático de [+AFETADO/ +PACIENTE] dos DPs na função sintática de sujeito e dos DPs na função sintática de objeto. A consequiência teórica que essa proposta traz para nossa análise é que teremos de admitir, então, que a partícula [.ke] está possivelmente 
associada à realização de Caso estrutural dos DPs. No âmbito da gramática gerativa, assume-se que Caso estrutural é responsável por tornar visível o papel temático dos DPs. Segundo Mioto et al. (2005, p. 174-175):
"a categoria gramatical de caso é necessária para qualquer língua na medida em que permite que os DPs sejam interpretados (...). Sem o caso, não seria possível recuperar qual o papel temático do DP. Esta necessidade de caso se verifica mesmo para línguas que não dispõem de um único morfema para este fim. Como todas as outras, esta língua precisa indicar qual o papel- $\theta$ do DP e isso é feito por meio do Caso abstrato".

Se essa proposta estiver mesmo correta, ficamos em condições de responder à questão levantada em (12), de sorte que postularemos que o escopo da partícula [.ke], na língua Ka'apor, constitui um dos mecanismos para realizar o Caso ${ }^{8}$ estrutural do DP sujeito de inacusativos e descritivos/ estativos e do DP objeto de verbos transitivos. Vejam que essa proposta encontra evidência adicional no fato de o sujeito $(\mathrm{So})$ e o objeto $(\mathrm{O})$ poderem ambos receber a partícula enclítica [.ke], conforme evidenciam os dados em (22) a (29). Nessas orações, verifica-se o alinhamento do DP sujeito dos predicados inacusativos e descritivos/estativos com o DP objeto do predicado transitivo. Uma possível explicação para esse alinhamento pode estar correlacionada com o que Dixon $(1979$, p. 89) denomina cisão determinada pela natureza semântica dos argumentos (S) dos verbos intransitivos:

\footnotetext{
“(...) na maioria dos exemplos de cisão condicionada pela natureza semântica dos verbos, afixos presos estão envolvidos; enquanto que, na maioria dos contextos de cisão condicionada pela natureza semântica dos NPs, ocorre marcação de caso nos argumentos. Isso é certamente o que podia ter sido predito: a cisão por meio de marcação morfológica condicionada pela natureza semântica do verbo é muito freqüentemente REALIZADA por meio de afixos no verbo; por sua vez, a cisão que é CONDICIONADA pela natureza semântica dos NPs é usualmente REALIZADA por meio de afixos ou partículas (de Caso) nos NPs.” [Grifo meu] [Dixon (1979, p. 89)]
} 
Notem que o padrão de marcação em Ka' apor parece coincidir exatamente com o previsto por Dixon, porquanto a cisão semântica condicionada pela natureza semântica dos predicados descritivos, conforme descrito na seção 1, é realizada por meio dos prefixos absolutivos. Já a cisão condicionada pela natureza semântica dos D/NPs é codificada por meio da partícula enclítica [.ke], conforme os dados em (22) a (29). Esse fato reforça nossa hipótese de que, em Ka'apor, a partícula [.ke] tem a função gramatical de tornar visível o papel temático [+AFETADO/+PACIENTE] e realizar o Caso estrutural dos DPs com os quais figura enclítica. No âmbito da tipologia sintática, costuma-se dar a esse Caso o rótulo de absolutivo.

Contudo, a mesma situação não se verifica com a codificação do sujeito (Sa) dos verbos inergativos e com a codificação do sujeito (A) dos verbos transitivos de ação, tendo em vista que, nesses predicados, os DPs agentivos na função de sujeito não vêm marcados pela partícula [.ke], conforme se vê pelos exemplos seguintes:

\section{INERGATIVOS}

$\begin{array}{llll}\text { jane } & \text { ja-jengar } & \text { ja-in } & \text { (Caldas, 2001, p. 47) } \\ \text { nós } & \text { nós-cantar } & \text { nós-estar } & \end{array}$

"Nós estamos cantando"

(31) ne re-wa:wak mi?

(Silva, 2001, p. 18)

tu tu-rodar PROB

"Tu rodastes?"

(32) jane ja-pikũj mi?

(Silva, 2001, p. 11)

nós nós-remamos PROB

"Nós remamos?"

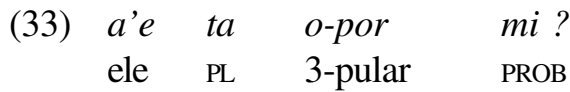

(Silva, 2001, p. 11)

"Eles pularam?"

(34) ihe a-je'eng a-in

(Silva, 2001, p. 12)

eu eu-falar eu-estar.sentando

"Eu estou falando sentando" 


\section{TRANSITIVOS}

(35)

ta'yn $_{\mathrm{j}} \quad h_{\mathrm{i}}$-okwen ke $\varnothing_{\mathrm{j}}$-nupa u-'am

criança POSS-porta ABS 3-bater 3-estar em pé

“A criança $\mathrm{j}_{\mathbf{j}}$ está (em pé) batendo à porta (dele(a) $\left.)_{\mathbf{i}}\right)$ " (Caldas, 2001, p. 50)

(36) isawi'a upa ihẽ ø-ma'e ke Ø-su'u:su'u rato tudo minha Poss-roupa ABS 3-roer:roer

"O rato roeu toda a minha roupa"

(Caldas, 2001, p. 53)

Tomando por base o contraste entre os dados (22) a (29), por um lado, e os dados em (30) a (36), por outro, notamos que o escopo sintáticosemântico da partícula [.ke] em predicados monoargumentais nos permite operar uma importante distinção gramatical entre verbos inacusativos e verbos inergativos. Portanto, o fato de os sujeitos agentivos dos predicados inergativos não receberem a partícula [.ke] servirá como um importante diagnóstico sintático para diferirmos as duas subclasses de verbos monoargumentais na língua Ka' apor. Chegamos, assim, ao seguinte sistema cindido de marcação de Caso dos argumentos nucleares A, Sa, So e O, na língua Ka'apor:

Sistema cindido de codificação dos argumentos em Ka'apor

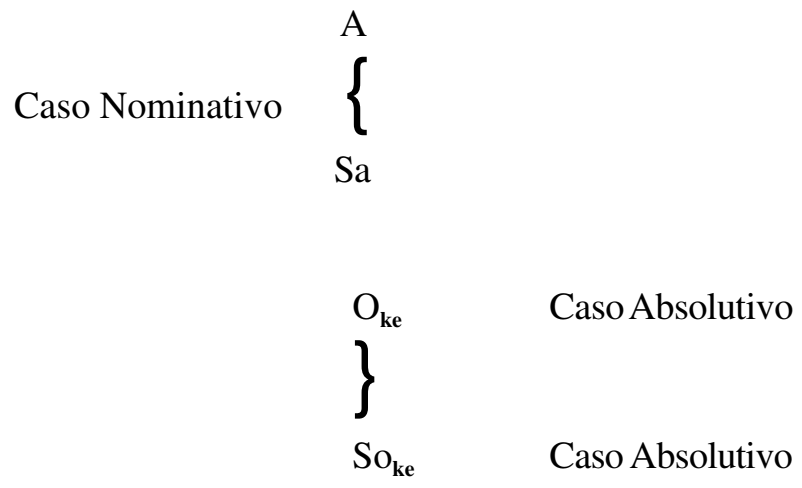


Vejam que o sistema em (37) é mais amplo e incorpora o sistema proposto em (21). Neste último, a cisão é determinada apenas pela natureza semântica do predicado descritivo/estativo e pela ocorrência dos prefixos absolutivos, enquanto, no sistema proposto anteriormente, a cisão está intimamente correlacionada com o escopo sintático-semântico da partícula [.ke]. Por conseguinte, a cisão de (S) em (37) nos permite alocar os verbos monoargumentais em, pelo menos, duas subclasses: a subclasse dos descritivos/ estativos e inacusativos, por um lado, e a subclasse dos inergativos, por outro, conforme mostramos pela lista de verbos na tabela 3 :

TABELA 3

Subclasses de verbos monoargumentais

\begin{tabular}{|c|c|c|}
\hline \multicolumn{2}{|c|}{$\begin{array}{l}\text { Predicados monoargumentais que marcam } \\
\text { DPs sujeito por meio da partícula } k e\end{array}$} & \multirow{2}{*}{$\begin{array}{l}\text { Predicados monoargumentais } \\
\text { que não marcam DPs com a } \\
\text { partícula } k e \\
\text { Inergativos }\end{array}$} \\
\hline Descritivos & Inacusativos & \\
\hline $\begin{array}{l}\text {-e’õ: ter cansaço } \\
\text {-yaj: ter suor } \\
\text {-pahar: ter pressa } \\
\text {-ky’a: ter sujeira } \\
\text {-pya'i: ter tristeza, } \\
\text { ter saudade, ter paixão } \\
\text {-aku: ter quentura } \\
\text {-juhar: ter coceira } \\
\text {-pu'i: ter finura } \\
\text {-katu: ter bondade } \\
\text {-ahy: ter dor } \\
\text {-akym: ter umidade } \\
\text {-axer: ter ruindade } \\
\text {-taj: ter ardor } \\
\text {-nge: ter sede } \\
\text {-risan: ter frio } \\
\text {-ka'u: ter tonteira } \\
\text {-membek: ser macio }\end{array}$ & $\begin{array}{l}\text {-kajum: perder, fugir } \\
\text {-pen: quebrar-se } \\
\text {-karuk: urinar } \\
\text {-manõ: morrer } \\
\text {-mano:ÿano: debater } \\
\text {-pak: acordar } \\
\text {-pyhyj: cochilar } \\
\text {-jixi’u: chorar } \\
\text {-hyk: chegar } \\
\text {-siryk: escorregar } \\
\text {-'ar: cair } \\
\text {-pyrii: tropeçar } \\
\text {-'e: apagar }\end{array}$ & $\begin{array}{l}\text {-xe: entrar } \\
\text {-jahuk: tomar banho } \\
\text {-pikũj: remar } \\
\text {-por: pular } \\
\text {-hem: sair } \\
\text {-wata: andar } \\
\text {-je’en: falar } \\
\text {-wapik: sentar-se } \\
\text {-ninõ: deitar-se } \\
\text {-pu’ãm: levantar-se } \\
\text {-ker: dormir } \\
\text {-jengar: cantar } \\
\text {-wa:wak: rodar } \\
\text {-jan: correr } \\
\text {-purahaj: dançar } \\
\text {-hendu: ouvir } \\
\text {-hem: gritar } \\
\text {-jawir: errar }\end{array}$ \\
\hline
\end{tabular}

Na seção 4, discutimos a atribuição do Caso nominativo e absolutivo à luz do Parâmetro Obrigatório de Caso (OCP), conforme Laka (1993) e Bobaljik (1993). Antes, faz-se necessário que apresentemos como os verbos 
descritivos, inacusativos, inergativos e mesmo transitivos podem mudar sua valência por meio do acréscimo do prefixo causativo $\{\mathrm{mu}-\sim \mathrm{m}-\}$. Nossa hipótese será que esse prefixo é a realização do verbo leve (light verb), o qual é juntado (merged) na posição de núcleo da projeção mais alta da concha v-VP.

\section{PROPRIEDADE GRAMATICAL DO PREFIXO CAUSATIVO $\{\mathrm{mu}-\sim \mathrm{m}-\}$}

Em Ka'apor, verbos podem, em princípio, se ergativizar ${ }^{9}$, alterando a sua valência por meio do acréscimo do prefixo causativo $\{\mathrm{mu}-\} \sim\{\mathrm{m}-\}^{10}$. Desse modo, esse morfema pode afixar-se a raízes de verbos descritivos, inacusativos, inergativos e, ainda, a raízes de verbos transitivos, resultando em uma mudança na valência dos predicados. Nota-se que esse prefixo vem antes da raiz verbal e situa-se depois dos prefixos nominativos, resultando na seguinte ordem interna dos prefixos verbais $\{\mathrm{AgR}+\mathrm{CAUS}+\mathrm{VERBO}\}$, conforme os dados seguintes:

\section{$\underline{\text { DESCRITIVO }} \rightarrow \underline{\text { ERGATIVO }}$}

(38a)
ihe $\varnothing$-'a
ke
i-akym
$\tilde{t}$
(Silva, 2001, p. 23)
meu poss-cabelo ABS
ABS-ter umidade REP
"O meu cabelo está molhado"

(38b)

$\begin{array}{llllll}a^{\prime} \boldsymbol{e} & \text { ihe } & \varnothing-' a & \boldsymbol{k} \boldsymbol{e} & \varnothing-\mathrm{mu} \text { - } a \text { kym } & \tilde{t} \\ \text { ele } & \text { meu } & \text { POSS-cabelo } & \text { ABS } & \text { 3-CAUS-ter umidade } & \text { REP }\end{array}$

"Ele fez o meu cabelo ficar molhado"

(39a) upa Ø-ma'e kase ke h-aku Ø-pytu (Silva, 2001,p. 23) tudo G-coisa café ABS ABS-ter quentura 3-ter manha "Todo o café está morno"
(39b) ihe
kase
ke
$a-m u-a k u$
eu
café
ABS
eu-CAUs-ter quentura

"Eu faço o café ficar quente"

\section{$\underline{\text { INACUSATIVO } \rightarrow \text { ERGATIVO }}$}

(40a) ihe

minha

$\varnothing$-je'e-ha

"Minha fala toda vai fugindo" ke upa

ABS tudo ø-kajim o-ho

3-perder-se 3-ir

(Silva, 2001, p. 18) 
(40b) ihe $\varnothing$-je'e-ha

ke upa a-mu-kajim

a-ho minha POss-falar-NOMI ABS tudo eu-CAUs-perder-se eu-ir "(Eu) faço a minha fala toda fugir"

\section{$\underline{\text { INERGATIVO } \rightarrow \text { ERGATIVO }}$}

(41a) ne

re-wa:wak

$m i$

(Silva, 2001, p. 19)

tu tu-rodar

PROB

"Tu rodastes?"

(41b) ihe

a'e

ke

a-mu-wa:wak

eu

ele

ABS

eu-CAUS-rodar

"Eu o fiz rodar"

(42a) jane

ja-jengar

nós

nós-cantar

ja-in

(Silva, 2001, p. 20)

"Nós estamos cantando"

(42b) ihe

a'e ke

nós-estar

eu

ele ABS

a-mu-jengar

"Eu o faço cantar"

eu-CAUS-cantar

\section{$\underline{\text { TRANSITIVO }} \rightarrow \underline{\text { ERGATIVO }}$}

(43a)
$a-s a k$
a'e ø-po
$r$-ehe
(Silva, 2001, p. 25)
"Eu vejo a mão dele"

(43b) ne

$\begin{array}{ll}\text { ihe } & \boldsymbol{k} \boldsymbol{e} \\ \mathrm{eu} & \mathrm{ABS}\end{array}$

re-mu-sak

'y

tu

$$
\text { estes ver" }
$$

Nas alternâncias apresentadas, observa-se que o DP sujeito dos exemplos em (a) é promovido a objeto do verbo ergativo e, geralmente, vem marcado com a partícula [.ke], situação sintática que sinaliza mudança do papel temático dos DPs sujeitos dos verbos inergativos e transitivos em (41a), (42a) e (43a), os quais assumem o papel temático [+AFETADO/PACIENTE] ${ }^{11} \mathrm{em}$ (41b), (42b) e (43b). Esta alteração de valência do predicado e do papel temático 
dos argumentos pode ser ainda sentida pela concordância que se estabelece entre o sujeito e o verbo. Por isso, nas sentenças em (b), a concordância sujeito-verbo só pode dar-se por meio do prefixo nominativo, nunca por meio do prefixo absolutivo.

Existe ainda a possibilidade de um verbo transitivo (indireto) ser ergativizado por meio do acréscimo do prefixo $\{$ mu- $\}$. Nesses contextos, o DP, que é o sujeito do verbo transitivo (indireto), é promovido para a função sintática de objeto direto do predicado ergativo e tem seu papel temático alterado, o que é sinalizado pela ocorrência da partícula [.ke]:
(44a) ne
re-parahy ihẽ
r-ehe
tu tu-ter raiva eu OBLIQ-de
"Tu tens raiva de mim"
(Silva, 2001, p. 24)

(44b) ihẽ ne ke a-mu-parahy

eu tu ABS eu-CAUs-ter raiva

"Eu te fiz ficar com raiva"

(Silva, 2001, p. 25)

(45a) ne re-py'a 'y $m$
tu tu-pensar NEG
“Tu não pensaste em mim"
(45b) a'e ne ke ø-ти-ру'a ihe r-ehe 'y
ele tu ABS 3-CAUS-pensar mim OBLQ-em PERF.1
"Ele te fez pensar em mim"

Quanto aos argumentos nucleares ${ }^{12}$, nota-se que a ordem sintática mais recorrente é SOV, conforme vemos nos exemplos anteriores e no exemplo (46) em que figura o verbo ergativo -mu-karuk "fazer urinar":

\section{ORDEM [SOV]}
(46) ihe
a'e ke a-mu-karuk
eu ele ABS eu-CAUS-urinar

(Silva, 2001, p. 21)

"Eu o faço urinar" 
Vemos que o prefixo $\{$ mu- $\sim$ m- $\}$ tem como função principal mudar a valência dos predicados verbais. Uma maneira de captarmos essa alternância é assumirmos que esse prefixo seja a instanciação, no âmbito do componente morfossintático, do verbo leve abstrato (light verb) na concha v-VP [cf. HALE e KEYSER (1993, 2000)]. Com base nessa hipótese, assumimos que o prefixo causativo $\{\mathrm{mu}-\sim \mathrm{m}-\}$ seja juntado como núcleo de vP, podendo, em princípio, c-selecionar tanto VPs transitivos quantos VPs intransitivos, conforme indicamos pelas representações seguintes:

\section{C-SELEÇÃO DE INACUSATIVOS EDESCRITIVOS/ESTATIVOS}

$\left[{ }_{\mathrm{vP}} \ldots . . \mathrm{mu}-{ }_{\mathrm{vP}} \mathrm{DP}_{\mathrm{ke}} \mathrm{V}\right]^{13}$

\section{C-SELEÇÃO DE INERGATIVOS}

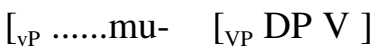

\section{C-SELEÇÃO DE TRASITIVOS DIRETOS}

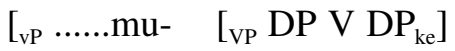

\section{C-SELEÇÃO DE TRASITIVOS INDIRETOS}

(50) $\left[{ }_{\mathrm{vP}}\right.$......mu- $\left[\mathrm{vP}_{\mathrm{mP}} \mathrm{DP}\right.$ PP $]$

Assim sendo, na sentença (51a), o prefixo causativo c-seleciona um VP monádico, o qual exibe, na posição de SPEC-VP, o DP [ne ke]. Suponhamos ainda que sua natureza afixal ${ }^{14}$ torne obrigatória a incorporação do verbo descritivo, resultando o verbo [-mu-purahý] "fazer ter raiva". A incorporação do verbo pode ser visualizada pela configuração sintática em (51b):
(51a) ihe
ne ke
a-mu-parahy
(Silva, 2001, p. 24)
eu
tu ABS
eu-CAUS-ter raiva

"Eu te fiz ficar com raiva" 
(51b)

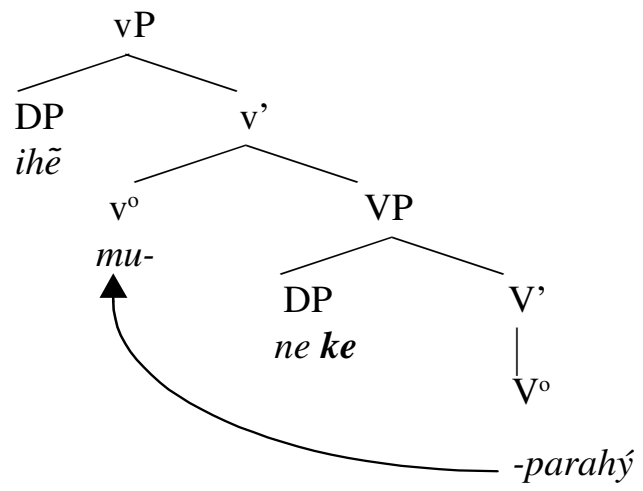

Veja que a ordem linear observada na sentença (51a) pressupõe que o movimento do verbo lexical para núcleo de vP deve ser seguida do movimento do DP objeto e do DP sujeito para posições em que possam verificar Caso. Se adotarmos a hipótese de que o Caso estrutural do objeto pode ser atribuído em SPEC externo de vP, então, segue-se que o DP objeto em (51a) se move para Spec-vP. Já o DP sujeito é elevado até SPEC-TP, posição em que recebe o Caso nominativo, conforme a derivação em (52):

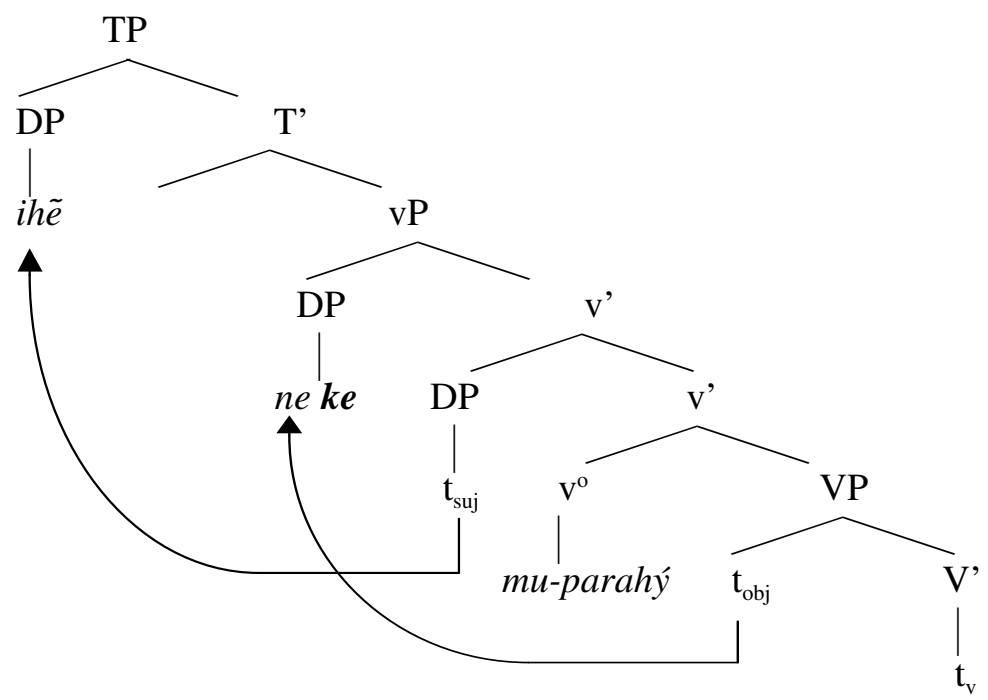


Por isso, a questão que se coloca para nossa análise é saber em que medida o movimento dos DPs para receber Caso (estrutural) está correlacionado com o Parâmetro Obrigatório de Caso (OCP) e com a natureza morfossintática dos núcleos $\mathrm{T}^{\mathrm{o}} \mathrm{e} \mathrm{v}^{\mathrm{o}}$. Na próxima seção, acompanhando a proposta de Laka (1993), Bobaljik (1993), Aldridge (2005) e Rackowski e Richards (2005), exploraremos a idéia de que, em Ka'apor, o núcleo $\mathrm{T}^{\circ}$ de orações transitivas, inergativas e inacusativa é inserido na derivação com o traço de Caso nominativo a atribuir aos DPs que sobem para a posição de Spec-TP. Por sua vez, em predicados estativos, $\mathrm{T}^{\circ}$ não estará ativo para atribuir Caso, de modo que, nesses predicados, será o núcleo $\mathrm{v}^{\circ}$ que atribuirá o Caso absolutivo aos sujeitos dos verbos descritivos. De maneira semelhante, nossa hipótese é a de que o núcleo $\mathrm{v}^{\mathrm{o}}$ nos predicados transitivos entra na derivação com o traço de Caso estrutural (absolutivo) a atribuir ao DP objeto.

\section{O PARÂMETRO OBRIGATÓRIO DE CASO}

Laka (1993) e Bobaljik (1993) desenvolvem uma teoria em que a atribuição do Caso ao único argumento de verbos intransitivos estará sujeita à parametrização, o que irá depender de qual Categoria funcional, responsável pela atribuição de Caso a esse argumento, estiver ativa. Assim sendo, numa língua nominativa, o único argumento do verbo monoargumental recebe Caso nominativo na posição de SPEC-TP, independentemente do fato de ser o verbo inacusativo ou inergativo. Já, em línguas ergativas, o sujeito do verbo intransitivo poderá receber o Caso absolutivo na posição de SPEC da projeção vP. Atribui-se o Caso ergativo/nominativo nos contextos em que há dois Casos a serem atribuídos: o ergativo ao DP sujeito e o absolutivo ao DP objeto, no sistema ergativo; e o nominativo ao DP sujeito e o acusativo ao objeto, no sistema nominativo. O parâmetro de atribuição de Caso não se aplica aos predicados transitivos, mas somente a predicados intransitivos, visto que ao sujeito (S) de verbos intransitivos poderá ser atribuído o nominativo ou o absolutivo, a ocorrência de um ou outro Caso dependerá das escolhas paramétricas de cada língua. Tomando por base a proposta de Laka (1993) e Bobaljik (1993), assumiremos que o Caso nominativo corresponde ao ergativo e o Caso acusativo, ao absolutivo. Em consonância com essa abordagem: 
“(...) 'ergativo' e ‘nominativo' são dois nomes diferentes para o Caso atribuído em Spec-Agr1 [i.e AgrsP] (....) e absolutivo/acusativo referem-se ao Caso atribuído em SPEC de AGR2 [i.e. AgroP] (....)”. [Bobaljik, (1993, p. 7)]

Uma maneira de adaptarmos essa proposta à estrutura da oração em que se eliminam as projeções AGRSP e AGRoP no mecanismo de verificação do traço de Caso é considerarmos que as duas categorias responsáveis pela atribuição dos Caso nominativo/ergativo e acusativo/absolutivo são TP e vP, respectivamente. Para facilitar nossa exposição, rotularemos o Caso nominativo/ ergativo atribuído por TP de C1 e o Caso acusativo/absolutivo atribuído por vP de C2, conforme mostramos pela configuração sintática seguinte:

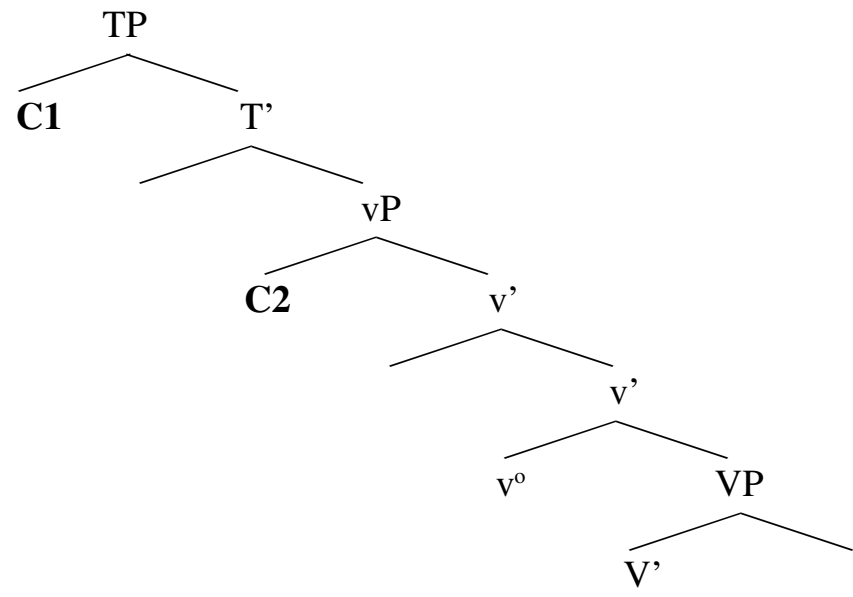

Levando-se em consideração que o parâmetro é de natureza binária e que pode ativar os $\mathrm{Casos} \mathrm{C}_{\text {nominativo }}$ ou $\mathrm{C} 2_{\text {absolutivo }}$ nos predicados monoargumentais, proporemos que o acionamento do Caso estrutural ao sujeito (S) pode resultar nas seguintes possibilidades tipológicas: 


\section{PARÂMETRO OBRIGATÓRIO DE CASO}

\section{LÍNGUAS NOMINATIVAS}

(54) $\mathrm{Se} \mathrm{C} 1_{\text {nominativo }}$ estiver ativo
(a) $\mathrm{V}_{\text {transitivo }}$
(b) $\mathrm{V}_{\text {intransitivo }}$
$\left(\mathrm{C} 1_{\text {nom }}, \mathrm{C} 2_{\text {acc }}\right)$
$\left(\mathrm{C} 1_{\text {nom }}\right)$

\section{LÍNGUAS ERGATIVAS}

(55) $\mathrm{Se} \mathrm{C} 2_{\text {absolutivo }}$ estiver ativo
(a) $\mathrm{V}_{\text {transitivo }}$
$\left(\mathrm{C} 1_{\text {erg }}, \mathrm{C} 2_{\text {abs }}\right)$
(b) $V_{\text {intransitivo }}$
$\left(\mathrm{C} 2_{\mathrm{abs}}\right)$

Exemplos de línguas que acionam positivamente a escolha paramétrica em (54) e que alinham (S) com (A) são o Inglês e o Latim, conforme os dados em (56a-c) e (57a-c). Notem que, em (57a-c), o Caso nominativo dos sujeitos de transitivos e intransitivos é atribuído pelo núcleo finito $\mathrm{T}^{\circ}$, o que se evidencia, por exemplo, pela concordância morfológica sujeito-verbo no Latim. Além disso, observa-se que o sistema de atribuição de Caso nessas línguas não reflete a distinção semântica entre verbos inacusativos e inergativos.

(56a) She $_{\mathrm{C} 1}$ saw her ${ }_{\mathrm{C} 2}$.

(56b) She ${ }_{\mathrm{Cl}}$ fell.

(56c) She ${ }_{\mathrm{Cl}}$ laughed.

(57a) Mullier $_{\mathrm{C} 1}$ mulierem $_{\mathrm{C} 2}$ vide.

(57b) Mullier $_{\mathrm{C} 1}$ cade.

(57c) Mullier $_{\mathrm{Cl}}$ ride.

Já no Inuit (cf. BOBALJIK, 1993), que é uma língua ergativa, o sujeito do verbo transitivo recebe o Caso ergativo, i.e., $\mathrm{C} 1$, e o sujeito do verbo intransitivo recebe o Caso absolutivo, i.e., C2, o mesmo que marca o objeto do verbo transitivo. Veja que essa marcação casual dos argumentos nitidamente contrasta com o paradigma exposto em (56) e (57). 


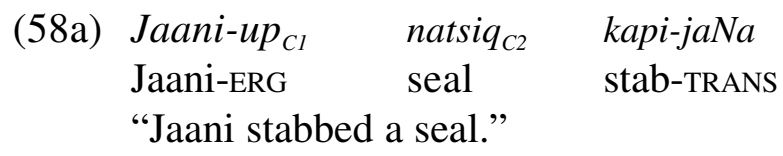

(58b) inuk C2 $_{\text {tikit-tuq }}$

person-ABS arrived

"The person arrived".
(58c) ilinniaqtitsiji ${ }_{C 2}$ uqaq-tuq
teacher-ABS spoke
"The teacher spoke."

Em síntese, vê-se que as línguas que acionam o sistema nominativo atribuem $\mathrm{C} 1$ ao sujeito do verbo intransitivo. Essa atribuição ocorre numa posição funcional mais alta, i.e., em Spec-TP. Além disso, só fazem uso da posição de atribuição de C2 na posição mais baixa quando existem dois DPs requerendo Caso, ou seja, em contextos de predicados transitivos. Já as línguas ergativas atribuem $\mathrm{C} 2$ ao sujeito do verbo intransitivo na posição funcional mais baixa, i.e., em SPEC-vP, que é a mesma posição estrutural em que o objeto recebe Caso (absolutivo) e C1 (=Caso ergativo) ao sujeito do verbo transitivo na posição funcional mais alta, i.e., em SPEC-TP.

A questão que se coloca para nossa análise é como conciliar o Parâmetro de Caso Obrigatório ao sistema cindido de marcação de Caso do Ka' apor, em que a atribuição de Caso ao sujeito do verbo monoargumental depende (i) da natureza semântica do predicado (estativo); (ii) do papel temático do DP e (iii) da concordância morfológica visível entre o sujeito e o verbo, conforme esquematizado no quadro em (37), repetido a seguir como (59): 
(59) Sistema cindido de codificação dos argumentos em Ka'apor

$$
\begin{aligned}
& \text { A } \\
& \text { Caso Nominativo } \\
& \{ \\
& \mathrm{Sa} \\
& \mathrm{O}_{\mathrm{ke}} \quad \text { Caso Absolutivo } \\
& \} \\
& \mathrm{So}_{\text {ke }} \text { Caso Absolutivo }
\end{aligned}
$$

Para explicarmos a cisão na atribuição do Caso a (Sa) e (So) dos verbos intransitivos da língua Ka' apor, proporemos alargar a gama de possibilidades tipológicas previstas pelo Parâmetro Obrigatório de Caso. Assim, além das possibilidades em (54) e (55), teremos uma outra em que C1 e C2 podem ser acionados simultaneamente, resultando na cisão em (59), conforme expomos em (60).

\section{PARÂMETRO OBRIGATÓRIO DE CASO}

\section{LÍNGUAS COM CISÃO NAATRIBUIÇÃO DE CASOA (SA) E (SO)}

(60) $\mathrm{Se} C 1_{\text {nominativo }}$ e $\mathrm{C} 2_{\text {acusativo/absolutivo }}$ são ativos
(a) $V_{\text {transitivo }}$
$\left(\mathrm{C} 1_{\text {nom }}\right.$,
$\left.\mathrm{C} 2_{\mathrm{abs}}\right)$
(b) $V_{\text {inergativo }}$
$\left(\mathrm{C} 1_{\text {nom }}\right)$
(b) $\mathrm{V}_{\text {inacusativo }}$
$\left(\mathrm{C} 2_{\mathrm{abs}}\right)$

A alternativa que existe é a de que línguas com sistema cindido exibem uma possibilidade tipológica não prevista em (54) e (55), visto que acionam SPEC-TP para atribuir C1 ao sujeito dos verbos inergativos e inacusativo e SPECvP para atribuir $\mathrm{C} 2$ ao sujeito dos verbos estativos e ao objeto do transitivo. Essa situação, na língua Ka'apor, fica particularmente evidenciada em virtude da ocorrência da partícula enclítica [.ke] a DPs que recebem o papel theta 
[+AFETADO/PACIENTE] e pela alternância entre concordância nominativa e absolutiva, conforme mostram os exemplos repetidos a seguir:
(61) Cristina $_{\mathrm{C} 1}$ ihẽ $\varnothing$-jiwa $\quad \boldsymbol{k e}_{\mathrm{C} 2} \quad \varnothing$-pyhyk (Caldas, 2001, p. 22)
Cristina meu POss-braço ABS 3-segurar
"Cristina segura meu braço"
(62) arauxu $_{\mathrm{C1}} \varnothing$-ahem uhu Araújo 3-gritar muito "Araújo gritou muito"

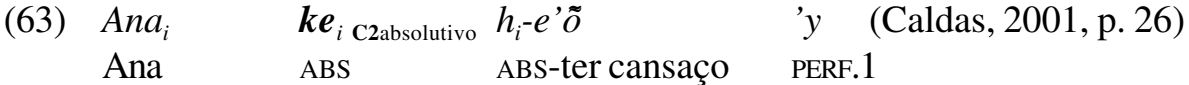 "Ana já cansou"

Uma questão fica em aberto: como pode ser que os verbos intransitivos possam atribuir Caso absolutivo/acusativo, conforme se nota em (63), tendo em vista a generalização de Burzio (1986), segundo a qual:
"um verbo somente pode atribuir Caso ao seu complemento se ele atribui papel theta ao seu agente. Em termos de relações estruturais, isso implica que um verbo somente pode atribuir Caso ao seu complemento se ele atribui um papel theta ao seu especificador" [cf. Holmer, (2001, p. 9) $]^{15}$

No entanto, dados das línguas que acionam o sistema ergativo, como o Inuit, e o sistema cindido, como o Ka'apor, mostram claramente que os chamados verbos inacusativos podem sim atribuir Caso estrutural ao seu complemento, contrariando assim a predição elaborada por Burzio (1986). Tal fato pode ser observado pelos dados em (58) e (63). Uma maneira de contornarmos essa questão pode ser encontrada se propusermos, então, que a generalização de Burzio (ibid.) é válida apenas para as línguas nominativas. Essa opção nos permite, por sua vez, propor que as línguas, dependendo de como o Parâmetro de Caso é acionado, podem ser agrupadas em dois grandes subtipos, a saber: 
(64) TIPO 1

Línguas acusativas

Generalização de Burzio se aplica

$\mathrm{C} 1_{\text {nominativo }}$ é acionado como o Caso do sujeito do verbo intranstivo

SPEC-TP é licenciado

É possível a voz passiva

\section{(65) $\underline{\text { TIPO } 2}$}

Línguas ergativas e cindidas

Generalização de Burzio não se aplica

$\mathrm{C} 1_{\text {nominativo }}$ ou $\mathrm{C} 2_{\text {acusativo/absolutivo }}$ podem ser acionados como o Caso do sujeito dos verbos intransitivos

SPEC-vP é licenciado

É possível a formação de antipassivas

Uma última questão que fica em aberto em nossa análise é saber qual é exatamente a posição estrutural que o DP sujeito de verbos inacusativos em Ka'apor recebe Caso. A hipótese que desenvolvemos é a de que essa posição corresponde a Spec-TP, e não a Spec-vP, apesar de a partícula [.ke] vir junto aos DPs sujeitos dos inacusativos, conforme sugere o exemplo (1), repetido a seguir como (66).

$\begin{array}{lll}\text { (66) ihe } & \boldsymbol{k} \boldsymbol{e} & \boldsymbol{a} \text {-'ar } \\ \text { eu ABS } & \text { eu-cair } \\ \text { "Eu caio" } & \end{array}$

(Silva, 2001, p. 47)

Essa hipótese é muito semelhante à análise desenvolvida por Aldridge (2005, p. 1-4), segundo a qual, em línguas ergativas, o Caso absolutivo pode ser checado pelos núcleos $\mathrm{v}^{\mathrm{o}}$ ou $\mathrm{T}^{\mathrm{o}}$, o que dependerá da transitividade do predicado. Nessa linha de raciocínio, a autora levanta várias evidências de que, na língua Tagalog, o núcleo $\mathrm{v}^{\mathrm{o}}$ de predicados transitivos possui traço EPP forte, o que explicará o movimento longo do DP objeto para o sistema $\mathrm{CP}$, em perguntas tipo-qu. No curso do movimento cíclico para Spec-CP, o objeto direto verifica o Caso absolutivo em Spec-vP. Já em predicados intransitivos, vP não possui traço EPP forte e também não licencia verificação do Caso absolutivo ao sujeito, visto que o núcleo com traço de Caso estrutural a ser 
atribuído é $\mathrm{T}^{\mathrm{o}}$. As evidências empíricas apuradas a partir da atribuição de Caso aos argumentos nucleares em Tagalog conduziram Aldridge (ibid.) a tomar uma direção oposta em relação ao que Murasugi (1992), Bittner e Hale (1996) e Ura (2000) assumem no âmbito do programa minimalista, segundo a autora:

"Caso absolutivo é valorado por v ou por T, dependendo da transitividade do verbo. Isso é uma posição distinta das abordagens tradicionais sobre ergatividade sintática (...) segundo a qual o Caso absolutivo é idêntico ao Caso nominativo. A posição assumida aqui é que DPs absolutivos não possuem necessariamente as propriedades de sujeito (...) Caso absolutivo em predicados transitivos, os quais são valorados em $\mathrm{v}$, funcionam mais como objetos do que como sujeitos, enquanto argumentos externos, independentemente se recebem Caso absolutivo ou Caso ergativo, comportam-se mais como sujeitos".

Tomando por base a teoria desenvolvida por Aldridge (2005), assumiremos então que $\mathrm{v}^{\mathrm{o}}$ em predicados inacusativos, no Ka'apor, não entra na derivação com traço-EPP forte nem possui traço de Caso estrutural (=absolutivo) a atribuir ao seu sujeito (i.e. ao argumento interno, gerado em Spec-VP). Nesse sentido, o núcleo que disponibilizará esse Caso será $\mathrm{T}^{\circ}$, e não ${ }^{\circ}$. Uma forte evidência a favor dessa análise surge do fato de que os sujeitos dos inacusativos, diferentemente dos sujeitos dos verbos estativos/descritivos, não engatilham a concordância sujeito-verbo por meio dos prefixos relacionais/absolutivos, mas, ao contrário, acionam somente a série dos prefixos pessoais nominativos. Por isso, a configuração seguinte indica que o local de verificação do Caso estrutural ao sujeito do verbo inacusativo é idêntica ao ponto na estrutura em que o sujeito dos verbos inergativos verifica o Caso estrutural. Nossa hipótese é que essa posição corresponde a Spec-TP, conforme a seguir. 


\section{(67)}

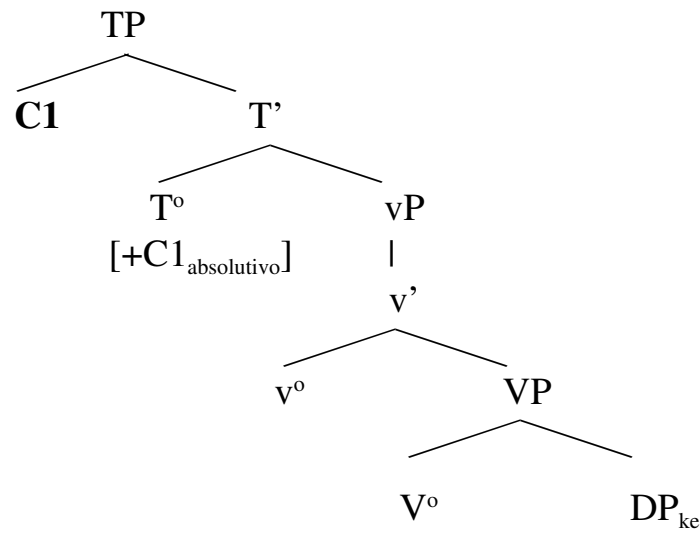

Veja que essa proposta está em consonância com a teoria desenvolvida por Alexiadou e Anagnostopoulou ${ }^{16}$ (2001, p. 211), segundo a qual os Casos nominativo e acusativo, por um lado, e ergativo e absolutivo, por outro, podem ser tratados formalmente como sendo idênticos; a diferença entre um e outro residirá apenas no fato de onde eles são licenciados na sentença. Nesse sentido, o que os dados do Ka' apor e de outras línguas ergativas (cindidas) sugerem é que o Caso absolutivo pode ser atribuído tanto pelos núcleos $\mathrm{v}^{0}$ quanto pelos núcleos $\mathrm{T}^{\circ}$, dependendo da natureza do predicado. Assim sendo, termos como nominativo, absolutivo, acusativo, ergativo, etc. seriam apenas rótulos descritivos. O que devemos considerar é a posição na estrutura em que o Caso estrutural dos DPs sujeito e objeto é licenciado.

\section{CONSIDERAÇÕES FINAIS}

Neste texto, mostramos que a língua Ka'apor possui um sistema de caso cindido que se caracteriza pela natureza semântica dos predicados e pela natureza semântica dos DPs. Com relação à primeira, pôde-se verificar que os predicados descritivos/estativos acionam prefixos absolutivos, enquanto os predicados inacusativos, inergativos e transitivos acionam os prefixos nominativos. A cisão de caso pela natureza semântica dos DPs se realiza por meio da partícula enclítica [.ke] que tem a função gramatical de realizar o papel temático [+AFETADO/+PACIENTE] e caso estrutural. DPs sujeitos de predicados 
descritivos/estativos, inacusativos e objetos de predicados transitivos serão marcados com a partícula [.ke]. Já DPs sujeitos de predicados inergativos e transitivos não recebem a partícula [.ke], sinalizando, por meio desse alinhamento, o caso nominativo. A cisão no sistema de caso por meio da natureza semântica dos DPs permitiu-nos, adicionalmente, distinguir os predicados monoargumentais em duas classes: os descritivos e inacusativos, por um lado, e os inergativos, por outro. Tal cisão não é determinada pela natureza semântica dos predicados, mas, ao contrário, tem por base o papel temático que o único argumento do verbo intransitivo $(\mathrm{Sa} / \mathrm{So})$ recebe.

Também verificamos que a alternância causativa nos permite propor a existência de, pelo menos, cinco subclasses de verbos, a saber: (i) descritivos/ estativos; (ii) inacusativos; (iii) inergativos; (iv) transitivos simples (direto e indireto) e (v) ergativos. Vejam que essas subdivisões sugerem que a distinção tradicional entre transitivos e intransitivos não agrega a possibilidade tipológica de uma distinção mais detalhada entre verbos intransitivos. Essa proposta proporciona uma análise mais refinada dos vários subtipos de verbos na língua Ka'apor.

Por fim, considerando a proposta de Laka (1993) e Bobaljik (1993), propusemos alargar o Parâmetro de atribuição de Caso de modo a dar conta de línguas que acionam cisão no sistema de caso como o Ka'apor. Nossa proposta é que, nessas línguas, existe uma terceira escolha paramétrica, a saber: o Caso do sujeito do verbo inergativo e inacusativo é licenciado em SPEC-TP e o Caso do sujeito do verbo estativo é atribuído em SPEC-vP, a mesma posição em que o objeto recebe Caso estrutural. Por fim, entretivemos a idéia de que ergativo/nominativo e acusativo/absolutivos são, ao final das contas, diferentes nomes para o mesmo fenômeno: o primeiro conjunto são nomes do Caso atribuído pelo núcleo $\mathrm{T}^{\mathrm{o}}$; o segundo são os nomes do Caso transmitido pelo núcleo $\mathrm{v}^{\mathrm{o}}$. 


\section{NOTAS}

${ }^{1}$ A língua Ka'apor pertence ao ramo VIII da família Tupi-Guarani juntamente com o Takunyapé, Wayampi, Wayampipukú, Emérillon, Amanayé, Anambé, Turiwára, Guajá (cf. RODRIGUES, 1985). Atualmente, os índios Ka'apor vivem na divisa dos Estados do Pará e do Maranhão. Estima-se que na região haja aproximadamente 1.000 índios distribuídos em onze aldeias, a saber:
(1) Xie pyhun r-enda
curió preto GEN-lugar
"Lugar do curió preto"
(2) Parakuy r-enda
paracuí GEN-lugar
"Lugar da Paracuî"
(3) Pakury-'y r-enda
bacuri-árvore GEN-lugar
"Lugar do bacurizeiro"

(4) Urutawy r-enda

coruja GEN-lugar

"Lugar da Coruja"

(5) ximbo r-enda

ximbo GEN-lugar

"Lugar do ximbó"

(6) waxĩngy r-enda

uaxingui GEN-lugar

"Lugar do uaxingui"

$$
\begin{array}{ll}
\text { arasa-ty } & r \text {-enda } \\
\text { arasa-plantação } & \text { GEN-lugar }
\end{array}
$$

"Lugar da plantação de arasa"

(8) pyky'a-'y r-enda

piquí-árvore GEN-lugar

"Lugar da árvore do Piqui"

(9) kumaru-'y r-enda

cumaru-árvore GEN-lugar

"Lugar da árvore Cumaru"

(10) jatahuty r-enda

babaçu GEN-lugar

"Lugar do Babaçu" 


\section{(11) xixindu \\ sítio novo \\ "Sítio Novo"}

${ }^{2}$ As orações analisadas foram coletadas dos estudos elaborados por Kakumasu, J. (1986); Corrêa da Silva (1997); Kakumasu, J. e Kakumasu, K. (1990), Silva (2001) e Caldas (2001). Em Kakumasu (1986), encontra-se uma proposta de descrição da língua Ka'apor baseada nas narrativas coletadas pelo autor. O trabalho de Corrêa da Silva (1997) trata de uma descrição diacrônica da língua Ka'apor comparando esta com as línguas Tembé, Wayampí, Tupinambá e a Língua Geral Amazônica. O trabalho de Kakumasu, J. \& Kakumasu, K. (1990) contém quinze narrativas indígenas que foram transcritas na década de 1960 na aldeia Água Preta. Mais especificamente, as transcrições foram documentadas nos anos de 1962 a 1965 e 1967. Os trabalhos de Caldas (2001) e Silva (2001) constituem uma descrição geral das classes verbais e dos morfemas de aspecto e modo em Ka' apor. O corpus das pesquisas de Caldas (2001) e Silva (2001) estão baseados em 62 horas de gravação com palavras, sentenças isoladas, narrativas indígenas, músicas cantadas e conversas espontâneas entre os índios Ka'apor.

${ }^{3}$ No âmbito da literatura gerativista, distinguem-se duas classes de verbos monoargumentais: os inacusativos e os inergativos.. Em consonância com Levin e Rappaport (1995, p. 3): "um verbo inergativo projeta um sujeito em estruturaD e nenhum argumento interno (=objeto), enquanto verbos inacusativos possuem um objeto na estrutura-D, seja ele uma oração ou um NP, e nenhum sujeito".

${ }^{4}$ Há uma alternância morfofonológica nos prefixos absolutivos. Quando o prefixo preceder uma raiz verbal iniciada por consoante, então teremos os prefixos zero $\{\mathrm{O}-\}$ e $\{\mathrm{i}-\}$. Já em raízes iniciadas por vogal, teremos os prefixos $\{\mathrm{r}-\}$ e $\{\mathrm{h}-\}$.

${ }^{5}$ Em Tenetehára, os prefixos $\{\mathrm{i}-\sim \mathrm{h}-\}$ podem denotar inclusive a elevação de DPs objetos para a posição de foco contrastivo, como se vê pelos exemplos seguintes, retirados de Duarte (2005, p. 18).
(ia) $\quad w$-exak
Fábio
Márcia
3-ver
Fábio
Márcia
"Fabio viu a Márcia"

$\begin{array}{lllll}\text { (ib) upaw Márcia } & \text { Fábio } & \boldsymbol{h} \text {-exak } & \boldsymbol{\emptyset} \\ \text { toda Márcia } & \text { Fábio } & \text { ABS-ver- } & \text { DESLOC } \\ \text { "ToDA A MárCIA, Fabio viu" } & & \\ \text { [lit: viu-a por inteiro, integralmente, e não parcialmente] }\end{array}$




(iia) $\begin{array}{ll}u \text {-'u teko pira } \\ \text { 3-comer a gente peixe } \\ \text { "Agente come peixe" }\end{array}$
(iib) upaw pira teko
todo peixe a gente ABS-comer-DESL
"ToDo O PEIXE, a gente come".

${ }^{6}$ A língua Guarani exibe uma cisão muito semelhante à do Ka' apor, visto que a classe de verbos estativo/descritivos, denominados por Gregorez e Suárez de verbos de qualidade (=quality verbs), também tomam os prefixos absolutivos. Conforme Dixon (1979, p. 83):

"verbos descritivos (...) apanham prefixos que são quase idênticos aos prefixos de objeto dos verbos transitivos. A maioria dos verbos descritivos corresponderiam a adjetivos em outras línguas, embora essa classe contenha verbos como 'lembrar'; 'esquecer'; 'contar mentira' e 'lamentar'”.

${ }^{7}$ Vejam o que afirma Kakumasu em relação ao escopo sintático-semântico da partícula [.ke]:

"O morfema ke normalmente segue um nome ou um sintagma nominal, incluindo pronomes e demonstrativos (...) Em orações intransitivas onde dois D/NPs figuram, um deles pode ser marcado com ke para indicar que o marcado é o objeto, este é o D/NP para o qual a ação é efetuada”. (Kakumasu, 1986, p. 350-351)

${ }^{8}$ Conforme Duarte (2005, p. 2), podemos afirmar que a categoria de Caso não é uma propriedade privativa das línguas que a exibem na morfologia, como é a situação do Latim, do Grego, do Alemão, do Russo, entre outras línguas. Chomsky (1981) incorpora a noção tradicional de Caso à teoria gerativa e postula que a marcação de Caso nos NPs deve ser entendida como um princípio universal da Gramática. Para Chomsky, todos os NPs foneticamente realizados precisam receber Caso abstrato na sintaxe, o qual pode ou não receber manifestação fonológica, o que dependerá das propriedades morfossintáticas das línguas particulares. Assim sendo, a diferença entre o Latim e o Português deve-se ao fato de haver ou não a realização de Caso no componente morfológico.

${ }^{9}$ Nas pesquisas da área da sintaxe e semântica, há dois sentidos para o termo ergativo. Um dos significados tem a ver com o caso ergativo que os DPs agentes assumem nos sistemas de caso ergativo-absolutivo. Nesse sistema, a língua trata os argumentos sujeito de verbo intransitivo (S) da mesma forma que o objeto de verbo transitivo $(\mathrm{O})$ codificando, assim, o caso absolutivo, e diferencia o sujeito 
agente de verbos transitivos (A), o qual recebe o caso ergativo (cf. DIXON, 1979, 1994; COMRIE, 1981; SEKI, 2000; WHALEY, 1997). Já no segundo significado, o termo ergativo faz referência aos verbos transitivos que alternam a sua valência, possuindo ora uma configuração diádica ora uma configuração monádica (=inacusativa). Exemplos: (i) O sol secou a madeira e (ii) A madeira secou. Nessa alternância da valência, há o rearranjo de argumentos nucleares, de maneira que o sujeito (S) do verbo intransitivo secar passa a ocupar a posição de objeto $(\mathrm{O})$ do verbo transitivo. Esse rearranjo lembra a marcação de caso ergativo apontado por Lyons (1968, p. 352), conforme citação a seguir:

“...o termo que é geralmente empregado pelos lingüistas para a relação sintática que se estabelece entre (i) The stone moved e (2) John moved the stone é o ergativo. Nessas construções, o sujeito do verbo intransitivo 'torna-se' o objeto de um verbo transitivo correspondente, e o novo sujeito ergativo é introduzido como o 'agente' (ou 'causador')."

${ }^{10}$ Em geral, o prefixo causativo $\{\mathrm{mu}-\}$ torna-se $\{\mathrm{m}-\}$ diante de vogais: $/ \mathrm{mu} / \rightarrow / \mathrm{m}-/ / \quad[+\mathrm{VOGAL}]$

${ }^{11}$ Para a classificação dos Papéis Temáticos, adotamos as propostas de Cançado \& Ciríaco (2005) e Cançado (2005) que consideram os papéis temáticos como um grupo de propriedades semânticas derivadas. Segundo as autoras, "os papéis temáticos não são noções primitivas, mas se definem como o grupo de propriedades atribuídas a um determinado argumento a partir dos acarretamentos estabelecidos por toda proposição na qual esse argumento se encontra." (CANÇADO \& CIRÍACO, 2005, p. 8). Algumas propriedades semânticas dos papéis temáticos estabelecidas por Cançado (2005) são:

(i) controle está associada a capacidade de se interromper uma ação, um processo ou um estado:

(a) João quebrou o vaso - João contém a propriedade de controle;

(ii) desencadeador faz referência ao argumento que desencadeia o evento:

(a) João quebrou a janela - João tem as propriedades de controle e desencadeador;

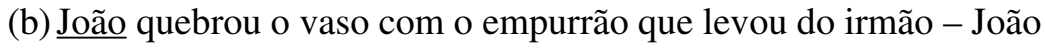
tem a propriedade de desencadeador;

(iii) Afetado corresponde à mudança de estado:

(c) João matou seu colega - colega possui a propriedade de afetado;

(d) João recebeu uma herança - João possui as propriedades de controle e afetado; 
(iv) Estativo é definida por não alterar as características do argumento num intervalo de tempo:

(f) João leu um livro - livro contém a propriedade de estativo

${ }^{12}$ Kakumasu (1986, p. 327) considera que a ordem predominante nas sentenças é SOV: "agora considero que SOV é a ordem de palavras básica na oração transitiva, e não OSV, como havia assumido em Kakumasu (1976). Em orações menos marcadas que possuem sujeito e objeto, a ordem mais freqüente é SOV." ${ }^{13}$ Consoante Hale e Keyser (1993, p. 16), “inacusativos são simplesmente verbos monádicos. O especificador, cuja projeção é um traço definidor da configuração de estruturas diádicas compostas, corresponde ao argumento interno" (...) - Ele é um especificador, não um complemento; aparece como um objeto somente nos usos sintáticos sentenciais apropriados dos alternantes relevantes".

${ }^{14}$ No italiano, Guasti (1997) aponta que predicados ergativos são formados pela gramaticalização do verbo lexical ao verbo causativo "fare", constituindo assim uma unidade morfossintática. Esta unidade entre o verbo causativo e o verbo lexical não pode ser quebrada. Entre as evidências que demonstram a unidade entre os dois verbos, a autora destaca os seguintes exemplos:

(a) Em predicados ergativos, o DP interno, o qual é gerado na posição de especificador do verbo lexical, sempre ocorre na posição pós-verbal:

(ia) Elena fa lavorare Gianni

(ib) *Elena fa Gianni lavorare

"Elena fez Gianni trabalhar"

(iia) Il trenó ha fatto arrivare Gianni in ritardo

(iib) *Il trenó ha fatto Gianni arrivare in ritardo "O trem fez Gianni chegar tarde"

(b) Em predicados ergativos, clíticos ocorrem sempre em próclise ao verbo causativo, conforme (iiia); enquanto, em predicados não ergativos, a ocorrência do clítico é em ênclise ao verbo lexical, conforme (ivb)

(iiia) Elena la fa ripare a Gianni

(iiib) *Elena fa riparela a Gianni

"Elena consertou o carro para Gianni" 
(iva) Gianni promise di leggere il libro

(ivb) Gianni promise di leggerlo

"Gianni prometeu ler o livro"

(c) Em predicados ergativos na forma passiva, o DP interno move-se para a posição de sujeito do verbo causativo:

(va) La machina ${ }_{i}$ è stata fatta riparare $t_{i}$ a Gianni

"O carro está sendo consertado por Gianni"

15 "a verb may only assign object Case to its complement if it assigns a thetarole to its agent. Expressed in terms of structural relations, this implies that a verb can only assign Case to its complement if it assigns a theta-role to its specifier (...)" [cf. Holmer, (2001, p. 9)]

${ }^{16}$ Consoante Alexiadou e Anagnostopoulou (2001, p. 211):

"there is no nominative Case feature distinct from an accusative Case feature. There is just a Case feature on $\mathrm{v}$ and a Case feature on $\mathrm{T}$. The two featues are identical for the computational system (....). They come out differently in the morphological component, which spells out accusative on the DP relating to the lower feature in opposition to the DP relating to the higher feature by virtue of the fact that accusative is a dependent case downward in accordance with a case realization hierarchy suggested by Marantz (1992)".

\section{REFERÊNCIAS BIBLIOGRÁFICAS}

ALDRIDGE, E. Phase theory account of absolutive extraction in Tagalog In: MCGINNIS, Martha; RICHARD, Norvin(Ed.). Perspectives on Phases. MITPWL \# 49, 2005.

ALEXIADOU, Artemis; ANAGNOSTOPOULOU, Elena. The subject-in-situ generalization and the role of case in driving computations. In: Linguistic Inquiry, MIT, p. 193-231, v. 32, number 2, Spring, 2001.

BOBALJIK, J. D. Ergativity and ergative unergativies. In: Phillips, C.; BOBALJIK, J. D. (Ed.). Papers on Case and agreement II. MITPWL \# 19, 1993.

BURZIO, L. Italian syntax: a government and binding approach. Dordrecht: reidel, 1986. 
CALDAS, Raimunda Benedita. Aspecto, modo de ação e modalidade na língua Ka'apor. 2001. 86p. Dissertação (Mestrado em Lingüística) - UFPA, Belém.

CANÇADO, Márcia; CIRÍACO, Larissa. Inacusatividade e inergatividade no PB. Cadernos de Estudos Lingüísticos, Campinas, 2005, no prelo.

. Propriedades semânticas e posições argumentais. DELTA, São Paulo, 2005, no prelo.

COMRIE, Bernard. Language Universals and Linguistic Typology. Chicago: Chicago Press, 1981.

CORRÊA DA SILVA, Beatriz. Urubú-Ka'apor, da gramática à história: a trajetória de um povo. 1997. 119p. Dissertação (Mestrado em Lingüística) Unb, Brasília.

CHOMSKY, Noam. Lectures on government and binding, Foris: Dordrecht, 1981. .The minimalist program. Cambridge: MIT Press, 1995.

DIXON, R. Ergativity. Language, v. 55, p.59-138, 1979.

. Ergativity. Cambridge: Cambridge University Press, 1994.

DUARTE, F.B. Análise grammatical das orações da língua Tembé. 1997. 95p. Dissertação (Mestrado em Lingüística) - Unb, Brasília.

Ordem de constituintes e movimento em Tembé: minimalismo e antisimetria. 2003. 198p. Tese (Doutorado em Lingüística) - UFMG, Belo Horizonte.

. Propriedades denotacionais dos prefixos $\{\mathrm{i}-\sim$-h $\}$ em Tenetehára. In: Revista de Estudos Lingüísticos/Gel, Campinas, Unicamp, 2005a.

. Codificação de argumentos e ergatividade (cindida) em Tenetehára, Revista Liames, Campinas: Unicamp/IEL, 2006a, no prelo.

. Caso, função sintática e papéis temáticos. Revista Duc in Altum, Muriaé: Faculdade Santa Marcelina, 2006, no prelo.

GUASTI, Maria Teresa. Romance causatives. In: HEAGEMAN, Liliane (Org.). The new comparative syntax, Longman, p.124-144, 1997.

HALE, Ken; KEYSER, Jay. Aspect and the syntax of argument structure, MIT, 1993, ms.

. The basic elements of argument structure. Rio de Janeiro: UFRJ, Curso de Estrutura das Línguas Indígenas Brasileiras, março 2000, ms. 
HOLMER, Arthur The ergativity parameter, In: Working papers \# 48, Lund University, p.101-113, 2001.

KAKUMASU, James. Urubu-Ka' apór. In: DERBYSHIRE, D. C.; PULLUM, G. K. (Org.). Handbook of Amazonian Languages, v. 1, p.326-403. New York: Mouton de Gruyter, 1986.

KAKUMASU, James Y.; KAKUMASU, Kiyoto. Outros textos urubu-kaapor. Brasília: SIL, 1990. 228 p. (Arquivo Linguiístico do Museu Nacional)

LAKA, Itziar. Unergatives that assign ergative, unaccusatives that assign accusative. In: PHILLIPS, C.; BOBALJIK, J.D. (Ed.). Papers on Case and agreement I. MITWPL \# 19, MIT, 1993.

LEVIN, B.; HOVAV, M. Rappaport. Unaccusativity: at the syntax-lexical semantics interface. Cambridge: MIT Press, 1995.

LOBATO, Lúcia M. P. Ergatividade: hipóteses gerativas e fatos de línguas Tupi, Brasília: UnB, Comunicação proferida durante o $1^{\circ}$ Encontro sobre Línguas e Culturas Tupi, 2004, ms.

LYONS, John. Introduction to theoretical linguistics. Cambridge: CUP, 1969.

MIOTO, Carlos; SILVA, Maria Cristina; LOPES, Ruth. Manual de sintaxe. 2. ed. Florianópolis: Insular, 2005.

RODRIGUES, A. D. Relações internas na família lingüística Tupi-Guarani. Revista de Antropologia, v. 27/28, p.33-53, 1985.

RACKOWSKI, A.; RICHARDS, N. Phase edge and extraction: a Tagalog case study. In: MCGINNIS, Martha; RICHARDS, Norvin (Ed.). Perspectives on Phases. MITPWL \# 49, 2005.

SAEED, John. Semantics. 2. ed. Oxford: Blackwell, 2003.

SEKI, Lucy. Gramática do Kamaiurá: língua Tupi-Guarani do Alto Xingu. Campinas: Unicamp, 2000.

SILVA, Tabita Fernandes. Classes verbais e algumas questões pragmáticas em Ka'apor. 2001. 79 p. Dissertação (Mestrado em Lingüística) - UFPA, Belém.

WHALEY, Lindsay. Introduction to Typology - the unity and diversity of language. London: Sage, 1997. 


\section{APÊNDICE}

\section{Abreviaturas}

ABs: caso absolutivo; AGR: agreement (concordância número-pessoa); Aux: verbo auxiliar; CAUS: morfema causativo; IMIN: iminente; INT: intenção; NOML: nominalizador; NEG: partícula de negação; PERF1: perfectivo de não-exclusividade; PL: partícula de plural; PROB: probabilidade; POSP: posposição, OBL: caso oblíquo; POSS: prefixo que indica o possuidor; REL: relativizador; REP: repetição; TRANS: transitividade; VER: verdadeiro, genuíno;

\section{Ortografia USADA}

Considerando o padrão fonêmico dos sons da língua Ka' apor, adotamos a seguinte ortografia cujo objetivo principal é facilitar a leitura dos dados usados em nossa análise. Os grafemas são:

(i) consoantes: p, t, k, kw, ', m, n, ng, ngw, s, x, h, r, w, j

(ii) vogais: (a) orais: i, y, e, a, o, u; (b) nasais: ̃̃ , y, ẽ, ã, õ, ũ

Os grafemas kw, ng, ngw, x, y, ' correspondem respectivamente aos seguintes fonemas: $\mathrm{kw}$ - oclusiva velar não-vozeada labial $/ \mathrm{kw} / \mathrm{ng}$ - nasal velar vozeada /y/; ngw - nasal velar labial vozeada / $\mathrm{yw} / ; \mathrm{x}$ - fricativa alveo-palatal / $/ ; \mathrm{y}-$

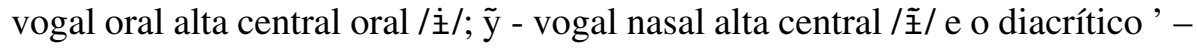
oclusiva glotal não-vozeada /?/. 